\title{
Scientometric Assessment of India's Migraine Research Publications during 2006-15
}

\author{
Ritu Gupta', B. M. Gupta², Jivesh Bansal ${ }^{3 *}$, Ashok Kumar ${ }^{4}$ \\ 'Department of Library and Information Science, Sri Venkateswara University, Tirupati-517502, INDIA. \\ ${ }^{2}$ Formely with CSIR-NISTADS, New Delhi, 1173, Sector-15, Panchkula-134 113, Haryana, INDIA. \\ ${ }^{3}$ A C Joshi Library, Panjab University, Chandigarh, INDIA. \\ ${ }^{4}$ M. M. University, Mullana-Ambala 133 207, Haryana, INDIA.
}

\begin{abstract}
The present study examines 579 Indian publications on "Migraine" research as covered in Scopus database during 2006-15, experiencing an annual growth rate of $17.37 \%$, citation impact per paper of 8.32 , international collaborative publication share of $9.80 \%$ and global publication share of $2.56 \%$. The global publications share on "Migraine" came from several countries, of which the top 10 most productive countries accounted for 75.30\% share of global publications output during 2006-15. A large number of Indian organizations and authors participated in Indian research on "Migraine" research during 2006-15, of which the top 15 organizations and 15 authors contributed $31.26 \%$ and $25.22 \%$ publications share and $70.50 \%$ and $23.50 \%$ citation share respectively of the Indian output and citations. Medicine, among subjects, contributed the largest publications $(63.90 \%)$, followed by pharmacology, toxicology \& pharmaceutics (34.72\%), neurosciences (14.16\%), biochemistry, genetics \& molecular biology (13.64\%) and chemistry (3.97\%) during 2006-15. Indian publications on migraine research appeared in several journals, of which the top 15 journals contributed $32.64 \%$ share of the India's
\end{abstract}

output. The top 14 highly cited papers registered 53 to 1087 citations, and together contributed 2094 citations, leading to the average citation per paper of 149.57. Concludes that there is an urgent need to frame a national policy in this area, undertake more $R \& D$ and recognize migraine research as a public health problem and allocate more healthcare funds in this area.

Key words: Migraine, Pain, Disease, Publications, India, Bibliometrics, Scientometrics.

Correspondence :

Jivesh Bansal,

A C Joshi Library, Panjab University, Chandigarh, INDIA.

Phone no: +91-9815440621

E-mail: jivesh@pu.ac.in

DOI: $10.5530 /$ jyp.2016.4.2

\section{INTRODUCTION}

Headache disorders are among the most common disorders of the nervous system and the most common patient complaints encountered in neurology practice, a fact borne out in prevalence estimates from numerous population-based studies. Headache can also be caused by or occur secondarily to a long list of other conditions, for example medication overuse headache. Headache disorders impose a recognizable burden on sufferers including sometimes substantial personal suffering, impaired quality of life and financial cost. Repeated headache attacks, and often the constant fear of the next one, damage family life, social life and employment. The long-term effort of coping with a chronic headache disorder may also predispose the individual to other illnesses. For example, depression is three times more common in people with migraine or severe headaches than in healthy individuals. ${ }^{1-2}$

A World Health Organization (WHO) review of global data found migraine to be one of the most prevalent health disorders worldwide, and the most frequent cause of headache consultation in the Americas, Europe, South-East Asia, and the Western Pacific. Among the 135 health conditions listed in the World Health Report 2001-Mental Health: New Understanding, New Hope, migraine was cited as $19^{\text {th }}$ leading cause of years lived with disability for both males and females worldwide. Globally, it has been estimated that prevalence among adults of current headache disorder (symptomatic at least once within the last year) is $47 \%$. Half to three quarters of the adults aged 18-65 years in the world have had headache in the last year and among those individuals, more than $10 \%$ have reported migraine. Headache on 15 or more days every month affects $1.7-4 \%$ of the world's adult population. Despite regional variations, headache disorders are a worldwide problem, affecting people of all ages, races, income levels and geographical areas. In the Global Burden of
Disease Study, updated in 2004, migraine on its own was found to account for $1.3 \%$ of years lost due to disability (YLD). ${ }^{1-2}$

The International Classification of Headache Disorders published by the International Headache Society, classify more than 150 types of primary and secondary headache disorders. The primary headache disorders are divided into four main groups: migraine, tension-type headache, trigeminal autonomic cephalgias and a miscellaneous group. Migraine headaches are characterized by throbbing and pulsating pain caused by the activation of nerve fibers that reside within the wall of brain blood vessels traveling within the meninges. Migraines headaches are recurrent attacks of moderate to severe pain that is throbbing or pulsing and often strikes one side of the head. Other common symptoms are increased sensitivity to light, noise, and odors; and nausea and vomiting. Routine physical activity, movement, or even coughing or sneezing can worsen the headache pain. Migraines occur most frequently in the morning, especially upon waking. Some people have migraines at predictable times, such as before menstruation or on weekends following a stressful week of work. Many people feel exhausted or weak following a migraine but are usually symptom-free between attacks. A number of different factors can increase your risk of having a migraine. These factors, which trigger the headache process, vary from person to person and include sudden changes in weather or environment, too much or not enough sleep, strong odors or fumes, emotion, stress, overexertion, loud or sudden noises, motion sickness, low blood sugar, skipped meals, tobacco, depression, anxiety, head trauma, hangover, some medications, hormonal changes, and bright. ${ }^{3}$

The two major types of migraine are: (a) Migraine with aura, previously called classic migraine, includes visual disturbances and other neurological symptoms. Individuals may temporarily lose part or all of their 
vision and (b) Migraine without aura, or common migraine, is the more frequent form of migraine. Symptoms include headache pain that occurs without warning and is usually felt on one side of the head, along with nausea, confusion, blurred vision, mood changes, fatigue, and increased sensitivity to light, sound, or noise. The other types of migraine include: (c) Abdominal migraine mostly affects young children and involves moderate to severe pain in the middle of the abdomen with little or no headache; (d) Basilar-type migraine mainly affects children and adolescents. It occurs most often in teenage girls and may be associated with their menstrual cycle; (e) Hemiplegic migraine is a rare but severe form of migraine that causes temporary paralysis-sometimes lasting several days-on one side of the body prior to or during a headache; (f) Menstrual-related migraine affects women around the time of their period, although most women with menstrual-related migraine also have migraines at other times of the month; (g) Migraine without headache is characterized by visual problems or other aura symptoms, nausea, vomiting, and constipation, but without head pain; (h) Ophthalmologic migraine an uncommon form of migraine with head pain, along with a droopy eyelid, large pupil, and double vision that may last for weeks, long after the pain is gone, (i) Retinal migraine is a condition characterized by attacks of visual loss or disturbances in one eye and (j) Status migrainosus is a rare and severe type of acute migraine in which disabling pain and nausea can last 72 hours or longer. ${ }^{3}$

\section{Literature Review}

There is no specific scientometric study on migraine research in the past. However, there are few studies undertaken by scholars from different countries on pain research. Among such studies, Leao, Aquarone and Rother ${ }^{4}$ analyzed 47 articles (involving 258 authors) addressing pain research published in indexed journals by professionals affiliated to a Research Institute of a non-for-profit general hospital of the city of São Paulo, from 2008 to 2011. Migraine (25.7\%) and headache (14.9\%) were most studied sub-themes, and epidemiological designs were the most observed (47\%). Sapunar, Kostit, Bano, Ferhatovi and Puljak ${ }^{5}$ evaluated number and type of Croatian publications in the field of pain research and to compare it with similar publications in Austria. The authors studied the number of publications, their impact factors and type of collaborations. Publications of Croatian authors in the field of pain research were compared with identical dataset comprising articles published by researchers from Graz, Austria, because of its comparable scientific production. From 1998 to 2011, scientists from Croatian institutions published 194 pain-related articles compared to 187 articles published by their peers from Graz. Onyeka and Chukwuneke ${ }^{6}$ studied the African pain research spectrum over the last 10 years, by analyzing 228 articles from 25 African countries published in 129 different journals. The authors identify the trends in the number of publications from different countries; identify the currently unexplored areas of pain research. Zhang, Yu, Chu and Dai ${ }^{7}$ analyzed 3683 publications related to headache research covered in PubMed in 2011 and analyzed country-wise and sub-field wise. Major emphasis in pain research research was on migraine research. Therapy, pathophysiology and etiology were the hot spots in research. Mogil, Simmonds and Simmonds ${ }^{8}$ analysed 4525 research papers published in journal Pain from its inception till the end of 2007 ( 32 years). The authors studied the characteristics of the pain research, subjects of study and clinical features of publications. Chuang and $\mathrm{Ho}^{9}$ studied highly cited articles in pain research published from 1900 to 2011. Their total number of papers and international collaboration statistics were presented for countries, institutions and authors.

\section{OBJECTIVES}

The main objectives of this study are to study the performance of Indian research on "Migraine" during 2006-15, based on publications output, as indexed in Scopus database. In particular, the study focuses on the following objectives: (i) To study the growth of world and Indian research output and its distribution by type of publication; (ii) To study the contribution \& citation impact of top 10 most productive countries; (iii) To study the share of international collaboration publications in India's output and share of leading collaborative countries; (iv) To study the distribution of Indian research output by broad subject areas; (v) To study the publication productivity and citation impact of leading Indian organizations and authors; and (vi) To study the leading media of communication and the characteristics of high cited papers.

\section{METHODOLOGY}

The study retrieved and downloaded the publication data of the world and of 10 most productive countries (including India) on "MIgraine" from the Scopus international multidisciplinary bibliographical and citation database (http://www.scopus.com) for 10 years during 2006-15. The keywords "Migraine" was used in "Abstract, Title and Keyword" tag and restricting it to the period 2006-15 in "date range tag" was used for searching the global publication data and this become the main search string. When the main search string with restricted to 10 most productive countries in "country tag", as shown below for India below, the publication data on 10 most productive countries were obtained. When the main search string is further restricted to "subject area tag", "country tag", "source title tag", "journal title name" and "affiliation tag", we got information on distribution of publications by subject, collaborating countries, organization-wise and journal-wise, etc. For citation data, open citation window is used, where citations are counted from the date of publication till March 2016.

TITLE-ABS-KEY(migraine) AND PUBYEAR > 2005 AND PUBYEAR $<2016$

TITLE-ABS-KEY(migraine) AND PUBYEAR > 2005 AND PUBYEAR $<2016$ AND ( LIMIT-TO(AFFILCOUNTRY,'India"))

\section{Analysis}

The global and Indian research output on migraine research consisted of 22658 and 579 publications during 2006-15, which increased from 2131 and 23 to 2168 to 69 publications from 2006 to 2015, registering annual average publication growth rate of $0.35 \%$ and $17.37 \%$. India's global publication share on migraine research was $2.56 \%$ during 2006-15, which increased from $1.73 \%$ to $3.34 \%$ from $2006-10$ to $2011-15$. The average citation per paper registered by Indian publications on migraine research was 8.32 during 2006-2015, which decreased from 13.01 to 6.01 from 2006-10 to 2011-15 (Table 1). Of the total Indian publications on migraine research, $69.60 \%$ (403) appeared as articles, $21.07 \%$ (122) as review papers, $4.84 \%$ (28) as letters, $2.07 \%$ (7) as editorials and others such as article in press, short surveys, books and book chapters less than 1.0\% during 2006-15.

India's share of international collaborative papers on migraine research was $9.80 \%$ during $2006-15$, which decreased from $11.5 \%$ to $9.0 \%$ from 2006-10 to 2011-15. (Table 1) Among the leading foreign collaborating partner countries in international collaborative research, the largest share $(60.0 \%, 36$ papers) came from USA, followed by U.K. (26.7\%, 16 papers), Italy, Germany and Norway (each $11.7 \%, 7$ papers), China (10.0\%, 6 papers), Australia, Brazil and Canada (each 8.3\%, 5 papers), etc during 2006-15. 


\section{Global Publications and Share of Top 10 Most Productive Countries}

The global share of top 10 most productive countries on migraine research consisted of 17062 publications, accounting for $75.30 \%$ share of world output during 2006-15, which increased from $74.38 \%$ to $76.16 \%$ from 2006-10 to 2011-15. The global publication share of top 10 most productive countries on migraine research individually varied from $2.56 \%$ to $31.82 \%$, with maximum share $(31.82 \%)$ coming from USA, followed by Italy (9.14\%), Germany (7.87\%), U.K. (7.37\%), Spain, Canada and France (from $3.36 \%$ to $4.33 \%$ ), Netherland, Turkey and India (from $2.56 \%$ to $2.77 \%$ ) from 2006-15. The global publication share increased highest by $1.61 \%$ in India, followed by Italy (1.17\%), USA ( $0.97 \%)$, Turkey (0.77\%), U.K. (0.54\%) and Canada (0.02\%), as against decrease by $1.65 \%$ in Spain, Germany (1.58\%), France $(0.05 \%)$ and Netherlands $(0.02 \%)$ from 2006-10 to 2011-15 (Table 2).

\section{Subject-Wise Distribution of Publications}

The publications output was classified according to Scopus bibliographical database subject classification. The largest share of publications (63.90\%) was classified under medicine, followed by pharmacology, toxicology \& pharmaceutics (34.72\%), neurosciences (14.16\%), biochemistry, genetics \& molecular biology (13.64\%) and chemistry (3.97\%) during 2006-15. The publication activity has increased in pharmacology, toxicology \& pharmaceutics (from $27.75 \%$ to $38.14 \%$ ), biochemistry, genetics \& molecular biology (from $8.90 \%$ to $15.98 \%$ ), as against decrease in medicine (from $71.73 \%$ to $60.05 \%$ ), neurosciences (from $19.37 \%$ to $11.60 \%$ ) and chemistry (from $6.81 \%$ to $2.58 \%$ from $2006-10$ to $2011-15$. Chemistry registered the highest citation impact per paper (13.13), followed medicine (8.92), biochemistry, genetics \& molecular biology (8.52), pharmacology, toxicology \& pharmaceutics (8.18) and neurosciences (7.37) during 2006-15 (Table 3).

\section{Sub-Fields of Migraine Research}

The largest number and share of research was focused on Migraine without Aura (46 papers, $7.94 \%$ share), followed by Migraine with Aura (44 papers, $7.60 \%$ share), Ophthalmologic Migraine (19 papers, 3.28\% share), Hemiplegic Migraine (12 papers, 2.07\% share), Retinal Migraine (7 papers, 1.21\% share), Abdominal Migraine and Basilar-Type Migraine (3 papers, $0.52 \%$ share each), and Menstrual- Related Migraine and Status Migrainosus (1 paper, $0.17 \%$ share each) during 2006-15. The publication share has increased in Migraine without Aura (from 7.85\% 7.99\%), Ophthalmologic Migraine (from 3.14\% to 3.35\%), Abdominal Migraine and Basilar-Type Migraine (from $0.0 \%$ to $0.52 \%$ each) and Menstrual- Related Migraine and Status Migrainosus (from $0.0 \%$ to $0.26 \%$ ), as against decrease in Migraine with Aura (from $10.47 \%$ to 6.19\%), Hemiplegic Migraine (from 2.09\% to 2.06\%) and Retinal Migraine (from $2.09 \%$ to $0.77 \%$ ) from 2006-10 to 2011-15 (Table 4).

\section{Significant Keywords}

Thirty six significant keywords (Table 5) have been identified in the migraine literature, which throw light on the nature of research carried out in this area

\section{Contribution and Citation Impact of Most Productive Organizations}

The top 15 organizations on "Migraine" research individually contributed 6 to 27 publications and together they contributed 181 publications (31.26\% publications share) which accounted for 4817 citations (70.50\% citation share) during 2006-15. A scientometric profile of top 15 most productive organizations is shown in Table 6. Five organizations contributed more than the average productivity per paper (12.07) of all organizations: Sanjay Gandhi Postgraduate Institute of Medical Sciences, Lucknow (27 papers), National Institute of Mental Health \& Neurosciences, Bangalore (19 papers), All India Institute of Medical Sciences, New Delhi (18 papers), Postgraduate Institute of Medical Sciences, Chandigarh (17 papers) and Vivekanda Institute of Medical Sciences, Kolkata (14 papers) during 2006-15. Two organizations received more than the average citations per paper (18.76) of all organizations: All India Institute of Medical Sciences, New Delhi (68.0) and Sanjay Gandhi Postgraduate Institute of Medical Sciences, Lucknow (47.96) during 2006-15. Four organizations received more than the average h-index (6.13) of all organizations: Sanjay Gandhi Postgraduate Institute of Medical Sciences, Lucknow (27), Baroda Medical College (12), All India Institute of Medical Sciences, New Delhi and National Institute of Mental Health $\&$ Neurosciences, Bangalore (7 each) during 2006-15. Four organizations registered more than average share $(8.29 \%)$ of international collaborative papers of all organizations: Panjab University, Chandigarh (42.86\%), National Institute of Mental Health \& Neurosciences, Bangalore (31.58\%), Dr Ram Manohar Lohia Hospital, New Delhi (28.57\%) and Lilavati Hospital \& Research Center, Mumbai (22.22\%) during 2006-15.

\section{Contribution and Citation Impact of Most Productive Authors}

The top 15 authors on "Migraine" research individually contributed 6 to 14 publications and together they contributed 146 publications $(25.22 \%$ publications share) which accounted for 1132 citations (23.50\% citation share) during 2006-15. A scientometric profile of top 15 most productive authors is shown in Table 7. Seven authors contributed more than the average productivity per paper (9.73) of all authors: A.Chakravarty and S.Prakash (14 papers each), K.Ravishankar, J.Kaita and R.Gupta (13 each), U.K.Mishra (12 papers) and M.S.Bhatia (10 papers) during 2006-15. Eight authors received more than the average citations per paper (7.75) of all authors: V.Lal (11.33), S.Pradhan (10.0), G.Gururaj (9.50), U.K.Mishra (9.42), J.Kaita (8.69), S.Prakash (8.50), M.S.Bhatia and S.K.Bhoi (8.30 each) during 2006-15.Four authors received more than the average h-index (5.0) of all authors: U.K.Mishra and J.Kaita (7 each), S.Prakash and R.Gupta ( $\wedge$ each) during 2006-15. Four authors registered more than average share $(8.22 \%)$ of international collaborative papers of all authors: G.Gururaj (83.33\%), G.B.Kulkarni (33.33\%), K.Ravishankar (23.08\%) and R.Gupta (15.38\%) during 2006-15.

\section{Medium of Communication}

Of the 579 Indian publications on "Migraine" research during 2006-15, 575 publications appeared in journals, 2 each in books and conference proceedings during 2006-15. The top 15 journals together contributed 189 publications, which accounted for $32.64 \%$ share of the total publication output during 2005-14. The publication share of 15 journals in total Indian publication output has decreased from 44.50 during 2006-10 to $26.80 \%$ during 2011-15. The largest number of publications (20) has appeared in Neurology India, followed by Annals of Indian Academy of Neurology and Journal of Headache \& Pain (19 publications each), Headache (17 publications, Cephalalgia (16 publications), International Journal of Pharmacy \& Pharmaceutical Science (14 publications, etc during 2006-15 (Table 8).

\section{High Cited Papers}

There were 14 high cited papers (1 paper with citation of 1087, 2 papers in citation range 121 to 148 and 11 papers in citation range from 53 to 84) which together received 2094 citations, accounting for average citation per paper of 149.57. Of the 14 high cited papers ( 8 articles and 6 reviews), 6 were single institution papers, 4 national collaborative and 4 international collaborative. The 14 high cited papers have appeared in 
Table 1: Annual Growth of Publications and Citations of Indian Migraine Research during 2006-15

\begin{tabular}{|c|c|c|c|c|c|c|c|}
\hline \multirow{2}{*}{$\begin{array}{c}\text { Publication } \\
\text { Year }\end{array}$} & \multicolumn{3}{|l|}{ World } & \multicolumn{3}{|c|}{ India } & \multirow[b]{2}{*}{ \%ТP } \\
\hline & TP & $\mathrm{TP}$ & $\mathrm{TC}$ & ACPP & ICP & $\% I C P$ & \\
\hline 2006 & 2131 & 23 & 480 & 20.87 & 6 & 26.1 & 1.08 \\
\hline 2007 & 2055 & 20 & 377 & 18.85 & 1 & 5.0 & 0.97 \\
\hline 2008 & 2215 & 35 & 288 & 8.23 & 4 & 11.4 & 1.58 \\
\hline 2009 & 2302 & 45 & 762 & 16.93 & 5 & 11.1 & 1.95 \\
\hline 2010 & 2344 & 68 & 578 & 8.50 & 6 & 8.8 & 2.90 \\
\hline 2011 & 2238 & 66 & 390 & 5.91 & 3 & 4.5 & 2.95 \\
\hline 2012 & 2311 & 93 & 1547 & 16.63 & 10 & 10.8 & 4.02 \\
\hline 2013 & 2479 & 95 & 212 & 2.23 & 8 & 8.4 & 3.83 \\
\hline 2014 & 2418 & 65 & 154 & 2.37 & 6 & 9.2 & 2.69 \\
\hline 2015 & 2168 & 69 & 29 & 0.42 & 11 & 15.9 & 3.18 \\
\hline 2006-10 & 11047 & 191 & 2485 & 13.01 & 22 & 11.5 & 1.73 \\
\hline 2011-15 & 11614 & 388 & 2332 & 6.01 & 35 & 9.0 & 3.34 \\
\hline 2006-15 & 22658 & 579 & 4817 & 8.32 & 57 & 9.8 & 2.56 \\
\hline
\end{tabular}

Table 2: Global Publication Output and Share of Top 10 Most Productive Countries on Migraine Research during 2006-15

\begin{tabular}{|c|c|c|c|c|c|c|}
\hline \multirow[t]{2}{*}{ Name of the Country } & \multicolumn{3}{|c|}{ Number of Publications } & \multicolumn{3}{|c|}{ Global Share of Publications } \\
\hline & 2006-10 & 2011-15 & 2006-15 & 2006-10 & 2011-15 & 2006-15 \\
\hline USA & 3460 & 3750 & 7210 & 31.32 & 32.29 & 31.82 \\
\hline Italy & 944 & 1128 & 2072 & 8.55 & 9.71 & 9.14 \\
\hline Germany & 959 & 825 & 1784 & 8.68 & 7.10 & 7.87 \\
\hline U.K. & 784 & 887 & 1671 & 7.10 & 7.64 & 7.37 \\
\hline Spain & 571 & 409 & 980 & 5.17 & 3.52 & 4.33 \\
\hline Canada & 371 & 392 & 763 & 3.36 & 3.38 & 3.37 \\
\hline France & 374 & 387 & 761 & 3.39 & 3.33 & 3.36 \\
\hline Netherlands & 307 & 321 & 628 & 2.78 & 2.76 & 2.77 \\
\hline Turkey & 256 & 358 & 614 & 2.32 & 3.08 & 2.71 \\
\hline India & 191 & 388 & 579 & 1.73 & 3.34 & 2.56 \\
\hline Total of 10 countries & 8217 & 8845 & 17062 & & & \\
\hline Total of the World & 11047 & 11614 & 22658 & & & \\
\hline $\begin{array}{c}\text { Share of } 10 \text { countries in world } \\
\text { output }\end{array}$ & 74.38 & 76.16 & 75.3 & & & \\
\hline
\end{tabular}

Table 3: Subject-Wise Distribution of Publications on “Migraine” during 2006-15

\begin{tabular}{|c|c|c|c|c|c|c|c|c|c|}
\hline \multirow[t]{2}{*}{ Name of the Subject } & \multicolumn{3}{|c|}{ No. of Papers } & \multicolumn{3}{|c|}{ Share of Papers } & \multirow[t]{2}{*}{$\mathrm{TC}$} & \multirow[t]{2}{*}{ ACPP } & \multirow[t]{2}{*}{$\mathrm{HI}$} \\
\hline & 2006-10 & 2010-15 & 2006-15 & 2006-10 & 2010-15 & 2006-15 & & & \\
\hline Medicine & 137 & 233 & 370 & 71.73 & 60.05 & 63.90 & 3299 & 8.92 & 22 \\
\hline $\begin{array}{c}\text { Pharmacology, toxicology \& } \\
\text { pharmaceutics }\end{array}$ & 53 & 148 & 201 & 27.75 & 38.14 & 34.72 & 1644 & 8.18 & 22 \\
\hline Neurosciences & 37 & 45 & 82 & 19.37 & 11.60 & 14.16 & 604 & 7.37 & 14 \\
\hline $\begin{array}{l}\text { Biochemistry, genetics \& } \\
\text { molecular biology }\end{array}$ & 17 & 62 & 79 & 8.90 & 15.98 & 13.64 & 673 & 8.52 & 11 \\
\hline Chemistry & 13 & 10 & 23 & 6.81 & 2.58 & 3.97 & 302 & 13.13 & 7 \\
\hline Total of India & 191 & 388 & 579 & 100.00 & 100.00 & 100.00 & & & \\
\hline
\end{tabular}

TC=Total Citations; ACPP=Average Citation Per Paper; HI=h-index. 
Table 4: Distribution of Papers by Type of Migraine Research during 2006-15

\begin{tabular}{|c|c|c|c|c|c|c|c|c|c|}
\hline \multirow{2}{*}{ Type of Migraine } & \multicolumn{3}{|c|}{ TP } & \multicolumn{3}{|c|}{ \%TP } & \multirow[t]{2}{*}{ TC } & \multirow[t]{2}{*}{ ACPP } & \multirow[t]{2}{*}{ HI } \\
\hline & 2006-10 & 2011-15 & 2006-15 & 2006-10 & 2011-15 & $2006-15$ & & & \\
\hline Migraine without Aura & 15 & 31 & 46 & 7.85 & 7.99 & 7.94 & 298 & 6.48 & 10 \\
\hline Migraine with Aura & 20 & 24 & 44 & 10.47 & 6.19 & 7.60 & 374 & 8.50 & 11 \\
\hline Ophthalmologic Migraine & 6 & 13 & 19 & 3.14 & 3.35 & 3.28 & 87 & 4.58 & 5 \\
\hline Hemiplegic Migraine & 4 & 8 & 12 & 2.09 & 2.06 & 2.07 & 107 & 8.92 & 4 \\
\hline Retinal Migraine & 4 & 3 & 7 & 2.09 & 0.77 & 1.21 & 37 & 5.29 & 3 \\
\hline Abdominal Migraine & 0 & 3 & 3 & 0.00 & 0.77 & 0.52 & 3 & 1.00 & 1 \\
\hline Basilar-Type Migraine & 0 & 3 & 3 & 0.00 & 0.77 & 0.52 & 3 & 1.00 & 1 \\
\hline $\begin{array}{c}\text { Menstrual- Related } \\
\text { Migraine }\end{array}$ & 0 & 1 & 1 & 0.00 & 0.26 & 0.17 & 0 & 0.00 & 0 \\
\hline Status Migrainosus & 0 & 1 & 1 & 0.00 & 0.26 & 0.17 & 1 & 1.00 & 0 \\
\hline Total of the country & 191 & 388 & 579 & & & & & & \\
\hline
\end{tabular}

Table 5: List of Significant Keywords in Migraine Literature during 2006-15

\begin{tabular}{ccccc}
\hline Name of Keyword & Frequency & S.No & Name of Keyword & Frequency \\
\hline Migraine & 406 & 19 & Migraine with aura & 42 \\
Headache & 160 & 20 & Diarrhea & 37 \\
Migraine disorders & 106 & 21 & Placebo & 36 \\
Drug efficacy & 76 & 22 & Ibuprofen & 35 \\
Nausea & 65 & 23 & Photophobia & 30 \\
Drug formulation & 63 & 24 & Zolmtriptan & 30 \\
Drug safety & 55 & 25 & Amitriptyline & 28 \\
Pain & 54 & 26 & Drug structure & 28 \\
Hypertension & 51 & 27 & Insomnia & 27 \\
Drug delivery system & 49 & 28 & Drug screening & 25 \\
Depression & 48 & 29 & Seizure & 24 \\
Diabetes mellitus & 47 & 30 & Skin diseases & 24 \\
Epilepsy & 47 & 31 & Alzheimer disease & 23 \\
Migraine without aura & 46 & 36 & Obesity & 23 \\
Drug release & 45 & 33 & Anxiety & 21 \\
Topiramale & 45 & 34 & Cardiovascular disease & 21 \\
Tension headache & 44 & 35 & Opthalmolegic migraine & 19 \\
Propranolol & 40 & 36 & Stroke & 17 \\
\hline
\end{tabular}

13 journals, of which the largest number (2) was published in AAPS PharmaSciTech and 1 paper each in Asian Journal of Andrology, Headache, Journal of Clinical Neurology, Journal of Clinical Pharmacology, Journal of Controlled Release, Journal of Ethno pharmacology, Journal of Urology, The Lancet, Neurology, Recent Patents on Drug Delivery \& Formulation, Tetrahedron and Trends in Molecular Medicine. The 14 high cited papers involve 18 Indian organizations, of which the highest number of papers (3) are published by M.S.University of Baroda, 2 papers by Centre for Cellular \& Molecular Biology, Hyderabad and 1 paper each by Postgraduate Institute of Medical Education \& Research, Chandigarh, Sanjay Gandhi Postgraduate Institute of Medical Sciences, Lucknow, , Maulana Azad Medical College, Delhi, SMS Medical College \& Hospital, Jaipur, Vector Control Research Center, Pondicherry, Institute of Nuclear Medicine
\& Allied Sciences, Delhi, Sambalpur University, University of Rajasthan, Jaipur, Dr H.S.Gour University, Sagar, Hamdard University, Jivraj Hospital, Ahmedabad, , KLE Society Hospital, Belgaum, Pancea Biotech Ltd, Mumbai, Betty Cowan Research and Innovation Center, Ludhiana, Glenmark Research Center, Mumbai and Shri Ramnath Singh Mahavidalaya, Bhind,

\section{SUMMARY}

The migraine research from India consisted of 579 publications during 2006-15, which increased annually from 23 to 69 from 2006 to 2015, having annual average publication growth rate of $17.37 \%$. India's publication share in global publication output was $2.56 \%$ during 2006-15, increasing from $1.73 \%$ to $3.34 \%$ from $2006-10$ to $2011-15$. Indian 
Table 6: Profile of Top 15 Most Productive Organizations on “Migraine" Research during 2006-15

\begin{tabular}{|c|c|c|c|c|c|c|}
\hline Name of the Organization & TP & TC & ACPP & $\mathrm{HI}$ & ICP & $\% \mathrm{ICP}$ \\
\hline Sanjay Gandhi Postgraduate Institute of Medical Sciences (SGPGIMS), Lucknow & 27 & 1295 & 47.96 & 27 & 1 & 3.70 \\
\hline National Institute of Mental Health \& Neurosciences, Bangalore & 19 & 116 & 6.11 & 7 & 6 & 31.58 \\
\hline All India Institute of Medical Sciences (AIIMS), New Delhi & 18 & 1224 & 68.00 & 7 & 1 & 5.56 \\
\hline Postgraduate Institute of Medical Sciences (PGIMER), Chandigarh & 17 & 133 & 7.82 & 4 & 0 & 0.00 \\
\hline Vivekanda Institute of Medical Sciences, Kolkata & 14 & 100 & 7.14 & 5 & 0 & 0.00 \\
\hline University College of Medical Sciences, Delhi & 12 & 85 & 7.08 & 5 & 0 & 0.00 \\
\hline Baroda Medical College & 12 & 108 & 9.00 & 12 & 0 & 0.00 \\
\hline Maulana Azad Medical College, Delhi & 11 & 109 & 9.91 & 4 & 0 & 0.00 \\
\hline Lilavati Hospital \& Research Center, Mumbai & 9 & 27 & 3.00 & 3 & 2 & 22.22 \\
\hline Chhatrapati Shahuji Maharaj Medical College, Lucknow & 8 & 24 & 3.00 & 3 & 0 & 0.00 \\
\hline SMS Pharma Research Center, Hyderabad & 7 & 19 & 2.71 & 3 & 0 & 0.00 \\
\hline Dr Ram Manohar Lohia Hospital, New Delhi & 7 & 18 & 2.57 & 1 & 2 & 28.57 \\
\hline Panjab University, Chandigarh & 7 & 84 & 12.00 & 4 & 3 & 42.86 \\
\hline Indian Institute of Chemical Technology, Hyderabad & 7 & 19 & 2.71 & 3 & 0 & 0.00 \\
\hline Punjabi University, Patiala & 6 & 35 & 5.83 & 4 & 0 & 0.00 \\
\hline Total of 15 organizations & 181 & 3396 & 18.76 & 6.13 & 15 & 8.29 \\
\hline Total of India & 579 & 4817 & & & & \\
\hline Share of 15 organizations in India's total output & 31.26 & 70.5 & & & & \\
\hline
\end{tabular}

$\mathrm{TP}=$ Total Papers; TC=Total Citations; ACPP=Average Citation Per Paper; ICP=International Collaborative Papers; HI=h-index.

Table 7: Profile of Top 15 Most Productive Authors on “Migraine" Research during 2006-15

\begin{tabular}{|c|c|c|c|c|c|c|c|}
\hline Name of the Author & Affiliation of the Author & TP & TC & ACPP & $\mathrm{HI}$ & ICP & \%ICP \\
\hline Chakravarty & $\begin{array}{c}\text { Vivekanda Institute of Medical Sciences, } \\
\text { Kolkata }\end{array}$ & 14 & 100 & 7.14 & 5 & 0 & 0 \\
\hline S. Prakash & $\begin{array}{l}\text { Smt B,K, Shah Medical Institute \& } \\
\text { Research Center, Piperia, Baroda }\end{array}$ & 14 & 119 & 8.50 & 6 & 0 & 0 \\
\hline K. Ravishankar & Jaslok \& Lilavati Hospital, Mumbai & 13 & 63 & 4.85 & 5 & 3 & 23.08 \\
\hline J. Kaita & $\begin{array}{c}\text { Sanjay Gandhi Postgraduate Institute of } \\
\text { Medical Sciences, Lucknow }\end{array}$ & 13 & 113 & 8.69 & 7 & 0 & 0 \\
\hline R. Gupta & $\begin{array}{c}\text { Himalayan Institute of Medical Sciences, } \\
\text { Dehradun }\end{array}$ & 13 & 94 & 7.23 & 6 & 2 & 15.38 \\
\hline U. K. Mishra & $\begin{array}{c}\text { Sanjay Gandhi Postgraduate Institute of } \\
\text { Medical Sciences, Lucknow }\end{array}$ & 12 & 113 & 9.42 & 7 & 0 & 0 \\
\hline M.S. Bhatia & $\begin{array}{c}\text { University College of Medical Sciences, } \\
\text { Delhi }\end{array}$ & 10 & 83 & 8.30 & 5 & 0 & 0 \\
\hline S. Pradhan & $\begin{array}{c}\text { Sanjay Gandhi Postgraduate Institute of } \\
\text { Medical Sciences, Lucknow }\end{array}$ & 9 & 90 & 10.00 & 5 & 0 & 0 \\
\hline B.M. Mittal & $\begin{array}{c}\text { Sanjay Gandhi Postgraduate Institute of } \\
\text { Medical Sciences, Lucknow }\end{array}$ & 8 & 60 & 7.50 & 5 & 0 & 0 \\
\hline S.K. Bhoi & $\begin{array}{l}\text { Sanjay Gandhi Postgraduate Institute of } \\
\text { Medical Sciences, Lucknow }\end{array}$ & 10 & 83 & 8.30 & 5 & 0 & 0 \\
\hline V. Lal & $\begin{array}{l}\text { Postgraduate Institute of Medical } \\
\text { Sciences, Chandigarh }\end{array}$ & 6 & 68 & 11.33 & 4 & 0 & 0 \\
\hline K. Ravikumar & $\begin{array}{c}\text { Indian Institute of Chemical Technology, } \\
\text { Hyderabad }\end{array}$ & 6 & 19 & 3.17 & 3 & 0 & 0 \\
\hline G.B. Kulkarni & $\begin{array}{l}\text { National Institute of Mental Health \& } \\
\text { Neurosciences, Bangalore }\end{array}$ & 6 & 37 & 6.17 & 4 & 2 & 33.33 \\
\hline G. Gururaj & $\begin{array}{c}\text { National Institute of Mental Health \& } \\
\text { Neurosciences, Bangalore }\end{array}$ & 6 & 57 & 9.50 & 4 & 5 & 83.33 \\
\hline \multirow[t]{4}{*}{ Mukherjee } & $\begin{array}{c}\text { Vivekanda Institute of Medical Sciences, } \\
\text { Kolkata }\end{array}$ & 6 & 33 & 5.50 & 4 & 0 & 0 \\
\hline & Total of 15 authors & 146 & 1132 & 7.75 & 5 & 12 & 8.22 \\
\hline & Total of India & 579 & 4817 & & & & \\
\hline & Share of 15 authors output in India's total & 25.22 & 23.5 & & & & \\
\hline
\end{tabular}


Gupta et al.: India's Migraine Research

Table 8: List of Top 15 Most Productive Journals on “Migraine" Research, 2005-14

\begin{tabular}{cccc}
\hline Name of the Journal & \multicolumn{3}{c}{ Number of Papers } \\
\cline { 2 - 4 } Neurology India & $2006-10$ & $2011-15$ & $2006-15$ \\
Annals of Indian Academy of Neurology & 11 & 9 & 20 \\
Journal of Headache \& Pain & 5 & 14 & 19 \\
Headache & 10 & 9 & 19 \\
Cephalalgia & 13 & 4 & 17 \\
\hline International Journal of Pharmacy \& Pharmaceutical Science & 12 & 4 & 16 \\
Research Journal of Pharmaceutical, Biological \& Chemical Sciences & 2 & 12 & 14 \\
International Journal Pharma \& Biosciencesi & 0 & 12 & 12 \\
International Journal of Pharmaceutical Science. Review \& Research & 3 & 10 & 11 \\
Journal of Clinical \& Diagnostic Research & 0 & 7 & 10 \\
Journal of Association of Physicians of India & 1 & 9 & 10 \\
Asian Journal of Pharmaceutical \& Clinical Research & 8 & 1 & 10 \\
International Journal of Pharmatech Research & 5 & 3 & 8 \\
BMJ Case Reports & 7 & 0 & 7 \\
Research Journal of Pharmacy \& Technology & 7 & 0 & 7 \\
Total of 15 journals & 85 & 104 & 189 \\
Total of India & 191 & 388 & 579
\end{tabular}

publications on migraine research registered an average citation impact per paper of 8.32 during 2006-2015, which decreased from 13.01 to 6.01 from 2006-10 to 2011-15. The share of international collaborative publications in India's output was $9.80 \%$, which decreased from $11.5 \%$ to $9.0 \%$ from $2006-10$ to $2011-15$. USA contributed the largest share (60.0\%) among India's international collaborative publications during 2006-15, followed by U.K. (26.7\%), Italy, Germany and Norway ( $11.7 \%$ each), China (10.0\%), Australia, Brazil and Canada (8.3\% each), etc during 2006-15. The global publications share on "Migraine" came from several countries, of which the top 10 most productive countries accounted for $75.30 \%$ share of global publications output during 2006-15. The largest global publication share(31.82\%) was contributed by USA, followed by Italy (9.14\%), Germany (7.87\%), U.K. (7.37\%), Spain, Canada and France (from $3.36 \%$ to $4.33 \%$ ), Netherland, Turkey and India (from $2.56 \%$ to $2.77 \%$ ) from 2006-15. The global publication share increased in India, Italy, USA, Turkey, U.K and Canada, as against decrease in Spain, Germany, France and Netherlands from 2006-10 to 2011-15. Medicine, among subjects, contributed the largest publications (63.90\%), followed by pharmacology, toxicology \& pharmaceutics (34.72\%), neurosciences (14.16\%), biochemistry, genetics \& molecular biology (13.64\%) and chemistry (3.97\%) during 2006-15. The publication activity has increased in pharmacology, toxicology \& pharmaceutics, biochemistry, genetics \& molecular biology, as against decrease in medicine, neurosciences and chemistry from 2006-10 to 2011-15. Chemistry registered the highest citation impact per paper (13.13), followed medicine (8.92), biochemistry, genetics \& molecular biology (8.52), pharmacology, toxicology \& pharmaceutics (8.18) and neurosciences (7.37) during 2006-15. Among the types of migraine research, the largest share of papers was contributed on Migraine without Aura (7.94\% share), followed by Migraine with Aura (7.60\% share), Ophthalmologic Migraine (3.28\% share), Hemiplegic Migraine (2.07\% share), Retinal Migraine (1.21\% share), etc. A large number of Indian organizations and authors participated in Indian research on "Migraine" research during 2006-15, of which the top 15 organizations and 15 authors contributed $31.26 \%$ and $25.22 \%$ publications share and $70.50 \%$ and $23.50 \%$ citation share respectively of the Indian output and citations. Indian publications on migraine research appeared in several journals, of which the top 15 journals contributed $32.64 \%$ share of the India's output, decreasing from $44.50 \%$ during 2006-10 to $26.80 \%$ during 2011-15. The top 14 highly cited papers registered 53 to 1087 citations, and together contributed 2094 citations, leading to the average citation per paper of 149.57. Amongst 14 high cited papers ( 8 articles and 6 reviews), 6 were single institution papers, 4 national collaborative and 4 international collaborative. The 14 high cited papers have appeared in 13 journals.

\section{SUGGESTIONS AND CONCLUSION}

Headache disorders are a public-health concern given the large amount of associated disability and financial costs to society. As headache disorders are most troublesome in the productive years (late teens to 50s), estimates of their financial cost to society - principally from lost working hours and reduced productivity - are massive. Yet, many of those troubled by headache do not receive effective care. Appropriate treatment of headache disorders requires professional training of health professionals, accurate diagnosis and recognition of the condition, appropriate treatment with cost-effective medications, simple lifestyle modifications, and patient education. Lack of knowledge among health-care providers is the principal clinical barrier. Worldwide, on average only four hours of undergraduate medical education are dedicated to instruction on headache disorders. Headache disorders are not perceived by the public as serious since they are mostly episodic, do not cause death, and are not contagious. The low consultation rates in developed countries may indicate that many sufferers are unaware that effective treatments exist. $50 \%$ of people with headache are estimated to be self-treating. Many governments, seeking to constrain health-care costs, do not acknowledge the substantial burden of headache on society. They might not recognize that the direct costs of treating headache are small in comparison with 
the huge indirect-cost savings that might be made (e.g., by reducing lost working days) if resources were allocated to treat headache disorders appropriately. WHO recognized the burden of migraine disorders in the early 2000's and in partner with non-governmental organization carried out a Global Campaign against Headache, initiated in 2004, with an aim to raise awareness of headache disorders, but also, to improve the quality of headache care and access to it worldwide. WHO also published the Atlas of headache disorders in 2011 describing the burden due to headache disorders and resources available to reduce them?.

\section{ABOUT AUTHORS}

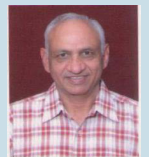

Ritu Gupta: Had completed his B.Lib. Sci. and M.Lib Sci degrees from Annamalai University and at present registered for Ph.D degree in the Department of Library \& Information Science at Sri Venkateswara University, Tirupathi, Andhra Pradesh. She has published more than 45 papers in the area of bibliometrics and scientometrics.

Dr B.M.Gupta: Is now a retired scientist. He was working as Emeritus Scientist in the National Institute of Science, Technology \& Development Studies (NISTADS), CSIR, New Delhi from 2008 to 2013. B.M.Gupta retired from CSIR as Scientist G in July 2008. Dr B.M.Gupta has completed B.Lib Sci from Kurukshetra University in 1971. Associatship in Documentation from INSDOC in 1975 and PhD from Karnatak University in 1999. Mr Gupta is the recipient of the Fullbright Professional Fellowship in Library \& Information Science (1999) and is elected the Fellow of the Society for Information Science (2007). Dr Gupta has more than 200 research papers mainly in the area of scientometricst, which are published in learned national and international journals.

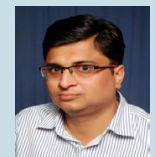

Dr. Jivesh Bansal: Is working as Deputy Librarian at Panjab University, Chandigarh. He has more than 16 years of professional experience, including 15 years vast experience at Central Library of Panjab University. He was awarded Ph.D. by Panjab University in 2013 for his doctoral research on 'Information Seeking Behaviour in Electronic Environment. Dr. Bansal has published more than a dozen papers in national and international journals. He contributed significantly in LIS conferences also. He served as resource person in several conferences/seminars/ workshops and training programmes.

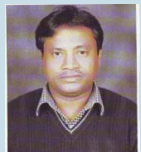

Dr. Ashok Kumar: Is currently working as a Chief Librarian in M. M. University, Mullana, Ambala, India. He has done his PhD from Kurukshetra University, Kurukshetra. He has more than fifteen years of experience in the field of Library \& Information Sciences. He is the Chief Editor of 'International Journal of Information Dissemination \& Technology'. His biography was published in 'Who's Who in the World-2015. He is the proud recipient of Limca Book of Records-2013. He has contributed more than 25 publications in various national and international journals of repute.

\section{REFERENCES}

1. Health Union, LLC. Migraine Prevalence and Incidence 2010-16 https://migraine. $\mathrm{com} / \mathrm{pro} /$ migraine-prevalence-and-incidence (Accessed on March 13, 2016)

2. WHO. Headache disorders, Fact sheet N²77, October 2012, Key factshttp:// www.who.int/mediacentre/factsheets/fs277/en/ (Accessed on March 13, 2016)

3. National Institute of Neurological Disorders and Stroke, National Institutes of Health, Bethesda, MD 20892. Headache: Hope through research. 3 November 2015. http://www.ninds.nih.gov/disorders/ headache/detail_headache.htm (Accessed on March 13, 2016)

4. Leao, Eliseth R, Aquarone, Rita L and Rother, Edna Terezinha. Pain research: bibliometric analysis of scientific publications of a Brazilian Research Institution. Revue Dor, Sao Paulo. 2013;14(2):94-9.

5. Sapunar, Damir, Kostit, Sandra, Bano, Adriana, Ferhatovi, Lejla and Puljak, Livia.
Pain research in Croatia: Analysis of bibliometric trends. Periodicum Bioloorum 2011,113(2), 137-40

6. Onyeka, Tonia and Chukwuneke, Felix N. Pain research in Africa: A ten year bibliometric survey. Journal of Anesthesia August. 2014;28(4):511-16

7. Zhang, Ming-jie, Yu, Sheng-yuan, Chu, Bing-qian and Dai, wei. A statistical analyses of perspective of headache related papers covered in 2011 in PubMed. Zhonghua Nei Ke Za Zhi. 2013;52(1):34-7.

8. Mogil, Jeffrey S, Simmonds, Kent and Simmonds, Maureen J. Pain research from 1975 to 2007: A categorical and bibliometric meta-trends analysis of research papers published in the Journal Pain. Pain. 2009;142(1-2):48-59.

9. Chuang, Kun-Yang and $\mathrm{Ho}$, Yuh-Shan. A bibliometric analysis of top-cited articles in pain research. Pain Medicine. 2014;15(5):732-44. 